\title{
Algumas observações acerca do discurso mental e do discurso verbal em Thomas Hobbes
}

Wladimir Barreto Lisboa

Universidade do Vale do Rio dos Sinos - UNISINOS

resumo Este artigo procura destacar algumas características do discurso racional em Thomas Hobbes. São analisadas as noções de prudência e ciência. 0 conhecimento racional repousará na possibilidade de construir, no discurso, um sinal - vox humana - que se sobreponha às marcas - notae - criadas pelos homens para excitar em nosso espírito um pensamento anterior. A seguir, são expostas as noções de proposição, nomes positivos e nomes negativos. Tais noções exibirão o determinismo hobbesiano, elemento determinante não apenas de sua philosophia prima, mas igualmente de sua teoria política.

palavras-chave Thomas Hobbes - discurso mental - discurso verbal - universal - determinismo; filosofia civil.

\section{Introdução}

Muito já se escreveu sobre a promessa feita por Hobbes de apresentar sua filosofia segundo um plano sistemático que partiria do simples ao composto, i.e., dos corpos simpliciter - o De Corpore, para, a seguir, tomálos enquanto dotados de um certo movimento intencional, o De Homine, e só então, na suposição do que havia sido apresentado anteriormente (a saber, a filosofia primeira e a ética), fornecer seus argumentos acerca da justificação racional deste corpo fictício denominado Respublica - o De Cive. Como é sabido, esta não foi a ordem de aparição dos textos. Em 1640 vem à luz os Elements of law, em 1642 o De Cive, em 1651 o Leviathã, e apenas em 1955 o De Corpore. Significaria isto o abandono por

Recebido em 15 de dezembro de 2005. Aceito em 17 de abril de 2006.

doispontos, Curitiba, São Carlos, vol. 3, n. 1, p.211-225, abril, 2006 
parte de Hobbes do anunciado projeto sistemático? Teria ele desenvolvido com inteira independência sua teoria política que, assim, dispensaria sua fundação em princípios estabelecidos em sua philosophia prima? Não nos parece ser este o caminho trilhado pelo filósofo de Malmesbury.

A fim de assentar os fundamentos da política (filosofia civil), a Ética deve primeiramente, aos olhos de Hobbes, proporcionar um fundamento racional às paixões internas do homem. Tal fundamento, por sua vez, não pode ser dissociado da fisica, pois estudar as paixões humanas significa considerar os dois movimentos invisíveis, interiores ao corpo humano: o apetite e a aversão. Entretanto, o conhecimento de tais paixões não pode repousar no discernimento de seus efeitos - o que conduz muitos comentadores de Hobbes a atribuir-lhe a tese, no mínimo parcial, do egoísmo racional, uma vez que, visto do ponto de vista das conseqüências, existe uma incomensurabilidade radical acerca daquilo que os indivíduos julgam ser um bem para si. Ao contrário, as paixões, para Hobbes, não podem ser conhecidas senão pelas causas - o que é o caso, aliás, para todo conhecimento (scientia). As causas das paixões encontram-se, segundo nosso autor, na sensação e na imaginação que são objeto de uma explicação mais geral acerca dos fenômenos da natureza, objeto de sua philosophia prima.

Ainda que sua filosofia primeira não tenha conhecido a mesma repercussão que obteve sua obra De Cive, ela é, não obstante, um dos maiores emblemas do pensamento filosófico do século XVII, talvez uma das primeiras "metafisicas" modernas, pela sua crítica radical a toda uma estrutura conceitual, sobretudo arisotélico-tomista, fundada em uma teoria modal acerca do existente que o distingue segundo os diferentes gêneros do ser. O projeto moderno de mecanização do mundo, conduzido pela análise privilegiada dos corpos segundo seu movimento (local), pressupõe diversas rupturas e acomodações com a tradição, muitas delas levadas a cabo por Hobbes, a começar pela computatio sive logica, primeira parte do De Corpore, onde se encontra, além de uma crítica aos nomes universais, uma teoria original acerca da significação dos nomes e dos erros categoriais a que é conduzida a linguagem natural. O Capítulo 6, último desta primeira parte, trata do método, do caminho à ciência. Nele encontramos em grande parte um debate cifrado com toda uma tradição, de Galeano, Aristóteles e Euclides aos paduanos, como Zabarella, acerca, 
dentre outras coisas, do modo segundo o qual devemos considerar o ponto de partida de um conhecimento em geral. A Philosophia prima, por sua vez, deve partir dos instrumentos fornecidos pela computatio e respeitar as interdições semânticas por ela estabelecidas. A essas considerações, deve-se acrescentar ainda a importância do determinismo no inteiro edificio da filosofia hobbesiana: o possível é aquilo que, em algum momento do tempo, se realizará.

Este trabalho procura, de um modo conciso, chamar a atenção para alguns destes conceitos que estruturam a "espinha dorsal" da filosofia de Hobbes.

\section{A imposição dos nomes e as definições}

Conhecer a diversidade dos movimentos pelos quais os acidentes ocorrem é, segundo Hobbes, conhecer as causas dos fantasmas, dos semblantes. Entretanto, o saber que provém da sensação não nos proporciona senão uma certeza prudencial (Cf. HOBBES, 1969, I, IV, 10, 16; HOBBES, 1968. p. 97-8). O poder cognitivo é, a este nível, ainda insuficiente para proporcionar um conhecimento causal do fenômeno, isto é, uma ciência do universal e do necessário (a única ciência possível). Ao nível da imaginação possuímos apenas um discurso mental, uma aproximação das imagens produzidas na sensação segundo o critério da similitude. A aproximação e distinção segundo a similitude das concepções são apenas conjecturais: a experiência proporciona apenas presunções do futuro ou conjecturas do passado (Cf. HOBBES, 1969, I, IV, 7 e 8, 15; HOBBES, 1973, XXX, 14, 344).

A experiência requerida pela prudência supõe que atribuamos os mesmos nomes às mesmas concepções. A imposição dos nomes visa a fazer retornar ao espírito a concepção da coisa nomeada (cogitatio praeterita) (HOBBES, 1973, XXX, 14, 344). Hobbes atribui o nome de nota-em latim " nota ", " mark " na edição inglesa - a uma concepção que traz ao espírito um fantasma similar àquele do passado. Em virtude da causalidade externa ininterrupta, procuramos reconstruir a cadeia causal através de nomes. Assim, ainda que a escolha de uma nota seja arbitrária, a função que ela possui na construção da experiência não o é, pois se não 


\section{4}

atribuíssemos os mesmos nomes às mesmas concepções, não teríamos experiência, "que nada mais é que a lembrança de que tais antecedentes foram seguidos de tais conseqüentes" (HOBBES, 1969, I, IV, 6, 14).

Se quisermos, entretanto, obter o conhecimento das causas dos acidentes que ocorrem nos diferentes corpos, isto é, se procuramos a ciência em geral, é preciso ir além das relações estabelecidas pela imaginação entre os objetos singulares. É necessário atingir enunciados universais e necessários. Com efeito, uma proposição é cientifica, segundo Hobbes, se afirma não apenas que um certo estado de coisas ocorre, mas também porque ele ocorre deste modo e não de outro. As proposições da ciência exprimem, portanto, as causas.

A apreensão de uma sucessão temporal pode ser compreendida de dois modos diferentes. Em primeiro lugar, temos uma consecução ou um encadeamento que conduz de um efeito imaginado até os meios que o produzem. Trata-se aí de uma conjectura sobre o passado e o futuro fundada na experiência. Todavia, é na segunda apreensão da sucessão temporal que reside a fonte da ciência. Ora, se a razão não dispõe senão de fantasmas produzidos na sensação, então a única possibilidade de fundar um conhecimento causal marcado pela necessidade e universalidade repousará na possibilidade de construir, no discurso, um sinal artificial que se sobreponha às marcas criadas pelos homens para excitar em nosso espírito um pensamento anterior. É preciso criar um artifício lingüístico destinado a significar não apenas cada um dos indivíduos, mas também o universal, concebido por Hobbes como o nome de cada uma das coisas às quais eles são comuns:

"A cadeia dos pensamentos regulados é de duas espécies: uma, quando, a partir de um efeito imaginado, procuramos as causas, ou meios que o produziram, e esta espécie é comum ao homem e aos outros animais; a outra é quando, imaginando seja o que for, procuramos todos os possíveis efeitos que podem por essa coisa ser produzidos ou, por outras palavra, imaginamos o que podemos fazer com ela, quando a tivermos. Desta espécie só tenho visto indícios no homem, pois se trata de uma curiosidade pouco provável na natureza de qualquer ser vivo que não tenha outras paixões além das sensuais, como por exemplo a fome, a sede, a lascívia e a cólera.” (HOBBES, 1983, p. 17) 
$O$ artificio do discurso humano consiste em construir um sinal lingüístico que nomeie uma diversidade de coisas particulares. Os nomes coletivos - as denominações universais como Hobbes as denomina, são artifícios humanos destinados a trazer ao espírito uma pluralidade de coisas reunidas por semelhança ou acidentes comuns. Construímos os universais para poder falar de uma multiplicidade de coisas que têm em comum certas características.

A operação destinada a construir os universais será então necessariamente distinta das operações que encadeavam os pensamentos dos individuais. Quais são, então, as operações responsáveis pela edificação destes artificios que permitem ao homem escapar à pura animalidade e construir algo absolutamente inédito, a saber, a ciência? Quando formulamos um enunciado como, por exemplo, "o morcego é um mamífero", o objetivo é o de falar de muitos morcegos individuais. Enunciar uma proposição universal é um expediente destinado a falar de uma multiplicidade de indivíduos simultaneamente. Isto não é possível senão pelo discurso racional. $\mathrm{O}$ universal pode, deste modo, apenas ser falado.

O universal é, pois, um instrumento lingüístico que não pode ser apresentado senão pelo discurso. É necessário determinar agora de que modo a razão produz esses artifícios responsáveis pela construção de um discurso causal, fundamento da ciência.

\section{0 raciocínio como cálculo}

Hobbes define assim a atividade da razão:

"Por raciocínio, entendo o cálculo. Ora, calcular é encontrar a soma de muitas coisas acrescentadas conjuntamente, ou encontrar o que resta de uma coisa da qual foi retirada uma outra coisa. Raciocinar é, pois, a mesma coisa que adicionar ou subtrair. Se alguém quer aditar, multiplicar e dividir, não me oponho, pois a multiplicação é apenas a adição de quantidades iguais e a divisão é a subtração da mesma quantidade, executada tantas vezes quanto possível. Todo raciocínio reduz-se, portanto, a duas operações do espírito, a adição e a subtração." (HOBBES, 1999, I, I, I, 2, 3) 


\section{6}

A atividade da razão é formada sob o modelo das operações aritméticas de adição e subtração. Esta operação, contudo, não se limita apenas aos números, mas se estende também ao inteiro campo do conhecimento:

"Não se pode crer que o cálculo, isto é, o raciocínio, somente tenha lugar nos números (...) pois a grandeza pode ser acrescentada à grandeza e ser dela retirada, do mesmo modo o corpo ao corpo, o movimento ao movimento, o tempo ao tempo, o grau da qualidade ao grau da qualidade, a ação à ação, a noção à noção, a proporção à proporção, o discurso ao discurso, o nome ao nome. Tudo isto é igualmente suscetível de adição e subtração, e é nestas coisas que consiste toda a filosofia.” (HOBBES, 1999, I, I, I, 3, 4-5)

Em uma passagem semelhante presente no Leviatã, Hobbes afirma que a razão, compreendida como adição e subtração, tem lugar não apenas entre os aritméticos (que ensinam a adicionar e a subtrair no domínio dos números), mas também entre os geômetras (que adicionam e subtraem linhas, figuras, ângulos, etc), entre os lógicos (que adicionam conjuntamente duas denominações para fazer uma afirmação, duas afirmações para fazer um silogismo, muitos silogismos para fazer uma demonstração, etc.), entre os autores de política (que adicionam em conjunto os pactos para encontrar os deveres dos homens) e, finalmente, entre os jurisconsultos (que adicionam em conjunto as leis e os fatos para encontrar o que é justo ou injusto na conduta dos particulares) (HOBBES, 1968, p. 110). O cálculo amplia, assim, seu domínio para além da esfera da aritmética. Ele toma uma significação filosófica. Através desta concepção da razão, Hobbes procede à identificação do cálculo com sua teoria geral do método:

"Os primeiros de todos os princípios da ciência são, pois, os fantasmas (phantasmata) dos sentidos e da imaginação que conhecemos naturalmente (naturaliter) que são. Mas conhecer por que eles existem, isto é, de qual causa provêm, é obra do raciocínio, que consiste (como dissemos no cap. I, art. 2.) na composição e divisão ou resolução. Todo método pelo qual investigamos as causas das coisas é, pois, compositivo ou resolutivo, ou em parte compositivo e em parte resolutivo. A resolução chama-se analítica e a composição sintética." (HOBBES, 1999, I, I, VI, 1, 59) 
Se nos reportarmos agora à indicação dada por Hobbes no De Corpore, cap. 1, art. 2, não encontraremos qualquer referência às noções de composição, resolução, análise ou síntese, mas apenas aos nomes de ratiocinatio, computatio, addere e subtrahere, o que reforça a idéia da indissociável conexão desejada por Hobbes entre o processo do raciocínio e o método resolutivo-compositivo. Conseqüentemente, o raciocínio é concebido como compreendendo as operações do espírito pelas quais este adiciona/compõe um todo a partir de suas partes ou subtrai/resolve um todo em suas partes. A incidência do cálculo se estende, assim, a tudo o que pode ser resolvido ou composto: "Estas operações não são características apenas dos números, mas também de toda a espécie de coisas que podem ser somadas juntas e tiradas umas das outras." (HOBBES, 1983, p. 27)

\section{II.1. A proposição verdadeira, os nomes negativos e a contradição}

Convém esclarecer, neste ponto, o domínio onde se estenderá o cálculo. Quando se trata da filosofia, não existe, afirma Hobbes, senão uma só espécie de discurso (oratio) concernida. Denominamo-lo de dito (dictum) ou enunciado (enunciatum) ou mesmo pronunciado (pronuntiatum), mas o mais seguidamente de proposição (propositio). Ela é afirmativa ou negativa, verdadeira ou falsa (HOBBES, 1999, I, I, III, 1, 27). O que enuncia uma proposição? Se a proposição é um discurso composto de dois nomes unidos pela cópula, então o cálculo terá por objeto os nomes. Ele estabelecerá, em uma proposição afirmativa, uma adição de dois nomes dos quais dizemos que o primeiro é um caso do segundo ou, formulado diferentemente, que o nome do sujeito está compreendido no nome do predicado.

Os nomes abstratos, por sua vez, são gerados em uma proposição na medida em que eles visam, no discurso, a exprimir a causa da atribuição do nome concreto, do nome do sujeito. Se tivermos sucesso nesta pretensão, diremos a verdade. Ao contrário, se fracassamos, estaremos no falso. A verdade depende, assim, da correta definição dos nomes. Do mesmo modo que os homens devem todo seu bom raciocínio aos discursos bem compreendidos, eles devem, do mesmo modo, todos seus erros ao discurso mal composto (HOBBES, 1999, I, I, III, 8, 32). 
Podemos agora demandar em quais circunstâncias um nome é rigorosamente definido. Pode-se afirmar que um nome é rigorosamente definido quando se mostrar possível determinar exatamente todos os objetos que estão compreendidos em seu domínio. Enquanto signos de nossos pensamentos, os nomes necessitam, para serem comunicados, da determinação de um campo de referência.

Para Hobbes, uma definição fixa a referência ao determinar a significação dos nomes. Ademais, uma definição não constitui a essência da coisa, mas um discurso que significa nossos conceitos sobre a essência da coisa (Cf. HOBBES, 1999, I, I, V, 7, 53). Ora, afirma Hobbes, quando temos sucesso em significar a essência, somos capazes de determinar não apenas todos os objetos que podem ser compreendidos no domínio do nome, mas igualmente todos os objetos que não fazem parte da extensão do nome. Assim, a definição fixa a referência dos pensamentos no contexto de um enunciado que visa a comunicação e, como conseqüência, estabelece também o domínio dos objetos que não entram na extensão do nome. Esta tarefa é realizada pelos nomes negativos.

"A primeira distinção a fazer entre os nomes é que uns são positivos ou afirmativos, os outros são negativos. Tem-se o costume de denominar estes últimos de privativos ou infinitos. Os positivos são aqueles que são dados às coisas as quais pensamos em virtude de sua similitude, de sua igualdade ou de sua identidade. Os negativos são aqueles que lhes são impostos por causa de sua diversidade, de sua diferença ou de sua desigualdade. Homem, filósofo, são nomes da primeira espécie, pois homem designa quem se quer dentre muitos homens, filósofo designa quem se quer dentre muitos filósofos, em virtude da semelhança que existe entre eles. Sócrates é ainda um nome positivo, pois ele designa um homem e sempre o mesmo. Os nomes negativos são aqueles que são construídos ao acrescentar a um nome positivo a partícula negativa: como o seria não-homem, não-filósofo.” (HOBBES, 1999, I, I, II, 7, 16)

Ora, quando determinamos um nome positivamente, constituímos também um domínio de exclusão, uma zona formada por todos os objetos que não entram no domínio dos nomes positivos. Se um nome não é rigorosamente definido, então não se pode discernir o verdadeiro do falso. Tomemos, a título explicativo, o nome branco dado a certas coisas. Se 
dispuséssemos apenas dos nomes positivos, não vislumbraríamos de que modo diferenciaríamos o nome branco dos nomes preto, azul ou diáfano. Esta dificuldade apareceria por que não poderíamos jamais conhecer a diversidade ou dessemelhança que nos permitiria identificar em todos os casos as coisas brancas e diferenciá-las de todas as outras coisas do mundo que não são brancas. A definição perfeita apenas pode ser obtida se dividimos o mundo absolutamente entre as coisas que são semelhantes ao branco e as outras coisas que são dessemelhantes e que, assim, não são brancas. Esta função não pode ser realizada senão pelos nomes negativos formados pelo acréscimo da partícula negativa ao nome. Apenas a negação permite, assim, dividir o mundo em dois campos absolutamente distintos, a saber, entre as coisas brancas e aquelas não-brancas:

"Pois, quando o nome branco foi dado a certas coisas e que, em seguida, os nomes preto, azul e diáfano foram impostas a outras coisas, as diferenças que existem entre cada uma dessas coisas que são em número infinito e o branco não puderam ser expressas senão por um nome que continha a negação do branco, tal como o de não-branco ou outro equivalente no qual a palavra branco se encontra (diferente do branco). Assim, pelos nomes negativos lembramos em nosso espírito e exprimimos aquilo que não tínhamos expressamente pensado."

(HOBBES, 1999, I, I, II, 7, 16-17)

Os nomes negativos não são, desse modo, nomes das coisas, mas dessemelhanças das coisas. Pelos nomes negativos, lembramos a nosso espírito e exprimimos o que não havíamos pensado expressamente. A função lingüística da negação cria, assim, uma diferença ao nível racional que explica operações que não podem ter lugar ao nível do discurso mental. O acréscimo da negação ao nome faz, desse modo, aparecer no discurso a contradição. $\mathrm{O}$ nome positivo e o nome negativo são contraditórios. Quando passamos dos nomes ao discurso, é a negação que permite compreender a possibilidade de dizer o verdadeiro através de definições bem formadas. Se assim for, então é necessário que aquele que afirma ou aquele que nega esteja no verdadeiro:

"Mas o nome positivo e o nome negativo são contraditórios entre si, de sorte que eles não podem ser, todos os dois, nomes da mesma coisa. Ademais, dos dois nomes contraditórios, um dos dois é sempre o nome 
de alguma coisa, pois tudo o que existe é homem ou não homem, branco ou não-branco, e assim por diante. (...) Todavia, a certeza deste axioma (que de dois nomes contraditórios um é sempre o nome de uma coisa qualquer e o outro não o é), esta certeza, digo, é o princípio e o fundamento de todo raciocínio, isto, de toda filosofia." (HOBBES, 1999, I, I, II, 8, 17)

Portanto, apenas há contradição se existe negação, e esta só opera na existência de uma diferença entre os nomes positivos e negativos. A versão ontológica do princípio de contradição - a mesma coisa não pode ser e não ser - é, segundo Hobbes, absurda, pois transpõe o que não existe senão no discurso às coisas elas mesmas.

Vimos a diferença entre os nomes positivos e negativos, e de que modo a negação engendra a contradição. Exibiremos agora de que modo a introdução da distinção entre os nomes próprios e os nomes comuns assegura uma operação da razão responsável pela universalização. Fornecidas a noção da negação (responsável pela possibilidade da negação) e a totalização (responsável pela universalização), estarão igualmente dadas as condições necessárias de um discurso racional.

\section{II.1.1. Os nomes comuns e os nomes próprios}

Entre os nomes, afirma Hobbes, alguns são próprios a cada coisa e denotam sempre uma entidade individual como, por exemplo, Homero, Pedro, João, este aqui, aquele lá. O nome comum, por sua vez, é o nome de muitas coisas tomadas uma a uma (e não de todas coletivamente). Tratase, portanto, de um nome universal que é sempre o nome de muitas coisas reunidas por alguma semelhança, como o são os nomes de animal, homem, pedra, etc.

$\mathrm{O}$ que permite a passagem dos nomes próprios à significação universal é, diz Hobbes, o discurso. Pedro e João são, cada um deles, individuais, pois não existe nenhum homem que não seja um dentre muitos homens. Do mesmo modo, não há nenhuma pedra, nenhuma árvore que seja universal. O que é então um universal se não há nada no mundo que lhe corresponda? Quando chamamos alguma coisa de animal, justifica 
Hobbes, é sempre de um animal determinado dentre os diversos animais que existem que estamos falando. Não falamos aqui de muitos animais, pois o animal não é qualquer animal indiferentemente, mas um animal determinado. O universal é assim uma voz $(v o x)$ que é o nome de muitas coisas; o singular, quanto a ele, é o nome de uma só coisa sempre singular (HOBBES, 1973, II, 6, 112). O universal é, desse modo, isto que é declarado de uma diversidade. A universalidade, em Hobbes, não é uma propriedade natural dos nomes, mas uma convenção adotada, um signo instituído para significar muitas coisas. Isto posto, duas teses podem ser formuladas. A primeira afirma que os universais são propriedades dos nomes e que, no mundo, apenas existem singulares. A segunda tese, característica de Hobbes, afirma que não apenas tudo o que existe é singular, mas também que as concepções da imaginação são, elas também, coisas individuais. $\mathrm{O}$ universal não se encontra nem nas coisas nem nas representações: ele está no discurso. Os universais são apenas nomes, sua compreensão não é a das coisas, mas a dos nomes ou, formulado mais corretamente, do discurso sobre os nomes.

Existe, portanto, uma ilusão que provém da confusão entre os nomes e as coisas. Ela se produz quando afirmamos a existência de entidades universais. Mas existe igualmente uma outra ilusão que consiste em transferir a universalidade dos nomes não às coisas, mas às suas concepções. A universalidade não é veiculada pelas representações (não se pode representar o universal), mas pelo resultado de uma convenção. Isto quer dizer que ela não depende de um determinado estado do mundo para existir. A natureza não é a causa disto que é universal. Supor o contrário significa transpor o domínio racional e proposicional ao discurso mental que lhe é anterior.

Assim, apenas um nome que é comum por convenção pode ser o nome de muitas coisas reunidas pela similitude, por suas relações. Um nome comum é, conclui Hobbes, o nome de muitas coisas, mas não coletivamente, isto é, a denominação universal não denota uma classe distinta dos indivíduos que a compõem, mas designa sempre distributivamente cada um dos indivíduos (Cf. HOBBES, 1973, II, 6, 113; HOBBES, 1999, I, II, XI, 19-20). 


\section{II.1.2. Os nomes, a proposição e o determinismo}

Vimos de que modo os nomes (nomina) instituem-se enquanto tais na medida em que se estabelece uma convenção de simbolização entre eles e as coisas nomeadas. Desse modo, quando dizemos "o homem é um animal", para que o enunciado seja significativo, supõe-se que o nome homem signifique alguma coisa e que o nome animal signifique também alguma coisa. O enunciado introduz uma ordem entre as concepções sensíveis que não é simplesmente uma ordem de sucessão, mas uma composição ou divisão dos nomes significando um estado de coisas (HOBBES, 1999, I, I, II, 8, 17). A diferença fundamental entre o discurso mental e o discurso verbal reside no fato de que neste último há um cálculo, isto é, uma adição ou subtração sob a matriz das concepções. $\mathrm{O}$ discurso mental, ao contrário, compõe-se de simples sucessão de concepções segundo o critério da comparação e está restrito a certos acidentes das imagens das coisas. Uma idéia ou uma concepção é sempre um instante na concepção da coisa (HOBBES, 1973, IV, 1, 125-26).

Em uma proposição temos, ao contrário, uma articulação de nomes. Esta articulação busca apresentar o primeiro nome como estando contido no segundo ou, dito diferentemente, a proposição procura apresentar o segundo nome como uma determinação do primeiro. Os nomes comuns permitem ao ser humano apresentar muitas coisas sob um mesmo nome. Os nomes ligados na proposição permitem passar do particular à consideração do universal. Os nomes negativos, por sua vez, fazem-nos lembrar e significar aos outros o que não pensamos. Ademais, eles tornam possível a definição na medida em que circunscrevem, juntamente com os nomes positivos, o inteiro domínio da identidade e não identidade disto que é definido. Os nomes comuns, por sua vez, permitem a universalização, condição do cálculo que adiciona e subtrai.

Deste modo, se tomarmos conjuntamente os nomes positivos e negativos em uma proposição, delimitamos todas as possibilidades de combinação dos estados do mundo, de modo que é absolutamente necessário que um dentre os dois se realize. De dois nomes contraditórios, diz Hobbes, um deles é sempre o nome de alguma coisa, pois tudo o que existe é homem ou não homem, branco ou não branco (HOBBES, 1999, I, I, II, 8, 17). Além disso, se enunciamos o par contraditório "Sócrates é 
homem e Sócrates não é homem”, obtemos uma contradição. Os dois enunciados não podem nem ser ambos verdadeiros, nem ambos falsos (HOBBES, 1999, I, I, III, 17, 37). Se for assim, então é necessário que um dos enunciados contraditórios seja atualmente verdadeiro, mesmo que não se saiba qual. Isso tudo implica, evidentemente, o determinismo: para toda proposição, passada, presente ou futura, ou bem ela ou bem sua contraditória é verdadeira. Tal determinismo decorre da admissão da natureza dos nomes positivos e negativos e do princípio de contradição tal como formulado por Hobbes. As contraditórias são proposições como, por exemplo, choverá amanhã ou não choverá amanhã. Estas duas proposições não podem ser nem as duas verdadeiras nem as duas falsas. $O$ fato de que, neste exemplo, as duas proposições versem sobre o futuro evidencia mais claramente a extensão do determinismo hobbesiano.

Se tal é o caso, então a noção mesma de ação humana parece estar sob suspeição. Se, para toda proposição, ou bem a afirmação ou bem sua negação é determinadamente verdadeira, então os estados do mundo que correspondem ao enunciado estão já dados, uma vez que a verdade de um enunciado implica justamente a realização disto que ele descreve. Nestas condições, como poderemos pensar que o homem é o agente de uma ação no mundo se todos os estados do mundo estão já determinados? No espaço deste artigo, apenas é possível apontar a direção da resposta a esta aporia.

Não há, para Hobbes, nenhuma incompatibilidade entre, de um lado, as diferentes afirmações que conduzem ao determinismo e, de outro, a ação humana em sua efetividade. Ao contrário, a tese do determinismo implicada pelo princípio de contradição e conjugada com a noção de causalidade decorrente de sua teoria física, constitui, antes, a condição mesma da ciência e, conseqüentemente, da ciência política. Esta última afirmação parece, entretanto, paradoxal. Com efeito, o domínio da política parece ser o teatro das ações humanas que se desenvolvem na dependência de procedimentos deliberativos escolhidos por agentes livres.

Entretanto, ao recusar a distinção entre necessidade simpliciter e necessidade hipotética, entre a ciência do que ocorre sempre e a ciência do freqüente, entre forma e matéria, Hobbes reafirma a idéia segundo a qual a totalidade dos fenômenos do mundo comporta apenas uma explicação 


\section{4}

mecânica segundo a causa eficiente. Toda explicação teleológica do mundo natural torna-se inconcebível.

Hobbes sustenta a exigência de uma racionalidade apodítica no domínio prático, chegando mesmo a inverter a célebre passagem da Ética a Nicômaco de Aristóteles segundo a qual não devemos exigir o mesmo rigor nos princípios dos quais partem o raciocínio prático e o raciocínio especulativo. A teoria hobbesiana consistirá em reafirmar este adágio aristotélico, mas ao inverso. É justamente porque devemos reclamar apenas o rigor que comporta a matéria, que as ciências humanas serão mesmo mais exatas que a fisica, disciplina exclusivamente especulativa e hipotética.

Finalmente, para a correta compreensão da resposta hobbesiana à aporia, faz-se necessário articular os conceitos hobbesianos de causalidade, de determinismo e de ciência com a noção de movimento enquanto elemento central na sua concepção de sistema filosófico. Isto feito, estaremos de posse dos elementos necessários para reconstruir sua teoria moral e política enquanto ciências, bem como esclarecer a ação humana que nela se justifica. Felizmente, este não é o objetivo deste artigo.

\section{Referências bibliográficas}

BERNHARDT, J. 1985. Nominalisme et Mécanisme dans la pensée de Hobbes. Archives de Philosophie, n. 48, p. 235-49.

HOBBES, T. 1973. Critique du De Mundo de Thomas White, édition J. Jacquot et H. W. Jones, Paris.

1999. De Corpore. Elementorum philosophiae sectio prima, édition

critique, notes, appendices et index par K. Schuhmann, Paris:Vrin.

1968. Leviathan, ed. MacPherson, Harmondsworth: Penguin Books.

1969. The Elements of Law Natural and Politic, ed. F.Tönnies, Londres: Frank Cass. 1983. Leviatã. São Paulo: ed. Abril. 
PECHARMAN, M. 1988. Métaphore et théorie des classes de noms chez Hobbes. Recherches sur la philosophie et le langage. Université de Grenoble II, n. 9, p. 99-119.

SCHUHMANN, K. 1999. Introduction au De Corpore. In HOBBES, T. De Corpore. Elementorum philosophiae sectio prima. Édition critique, notes appendices et index par K. Schuhmann, Paris:Vrin.

ZARKA,Y. C. 1987. La décision méthaphysique de Hobbes. Condition de la Politique. Paris:Vrin. 